\title{
O ESTUDO DO MOVIMENTO CONSIDERANDO ASPECTOS MATEMÁTICOS E HISTÓRICOS VISANDO A COMPREENSÃO DAS CONCEPÇÕES DA AÇÃO LOCAL E DA AÇÃO À DISTÂNCIA.
}

\author{
Jonathan Cedraz Rios ${ }^{1}$; Milton Souza Ribeiro Miltão ${ }^{2}$; \\ 1. Bolsista PROBIC/UEFS, Graduando em Bacharelado em Física, Universidade Estadual de Feira de \\ Santana, e-mail: jonathanrioos13@gmail.com \\ 2. Orientador, Departamento de Física, Universidade Estadual de Feira de Santana, e-mail: \\ miltaaao@gmail.br
}

PALAVRAS-CHAVE: Ação à Distância; Ação Local; Movimento.

\section{INTRODUÇÃO}

O intuito desse trabalho é fazer um estudo histórico do movimento e buscar a sua compreensão ao longo do tempo, para possibilitar o entendimento das concepções de ação local e à distância. Os estudos relacionados com esse tema por estudiosos que buscavam descrevê-lo, visando compreender qual era sua causa, podem ser encontrados em textos clássicos que estão sendo tomados como base para o desenvolvimento e aprimoramento da compreensão acerca do movimento. Com base em nossa experiência, no estudo da Mecânica, que fornece uma teoria e lei geral da Física que é responsável pela investigação do movimento e das forças que o produzem, podemos constatar a importância singular do tema, sendo possível um aprofundamento de conceitos utilizados na Física, como: as equações do movimento de um corpo ou sistema, a ação de forças, a teoria da gravitação tanto com uma visão Newtoniana quanto do ponto de vista da relatividade geral de Einstein, além de outro importante tema que está interligado ao estudo do movimento, que é a escolha de um referencial para a descrição do fenômeno. Com isso, atingimos o objetivo do trabalho que é compreender a concepção da ação local e à distância em suas características históricas, bem como matemáticas.

\section{MATERIAL E MÉTODOS OU METODOLOGIA (ou equivalente)}

Na primeira etapa do projeto foi feito um programa de estudos de revisão dos conhecimentos básicos que dão suporte para a compreensão do fenômeno do movimento e compreender questões importantes como: o referencial, as forças agindo sobre o sistema entre outros conceitos, a partir de textos clássicos que tratam do assunto. Foram discutidos problemas básicos para uma perfeita assimilação de tais conteúdos. A evolução do programa de estudos foi acompanhada rigorosamente com a discussão de problemas de forma aberta, na forma de seminários, e textos produzidos pelo bolsista, ao fim de cada bloco de conteúdo. Depois dessa fase, parte-se para o estudo dos artigos científicos que abordam essa problemática e, assim, o estado da arte de tal problema ficar bem delimitado. Para a segunda etapa o candidato pôde está apto a compreender o conceito do movimento com noções históricas e matemáticas.

\section{RESULTADOS E/OU DISCUSSÃO (ou Análise e discussão dos resultados)}

A relação do ser humano com o movimento é tão antiga que ele, digo o movimento, pôde influenciar diretamente na organização coletiva daquelas primeiras civilizações. O estudo da mecânica, a matemática, a geometria e outras áreas ganham destaque na civilização grega, sendo Aristóteles um dos precursores a se arriscar a 
pensar em questões acerca do movimento propondo a existência de dos tipos: o movimento natural, o que é desprovido de ação externa e o movimento violento que existe em consequência dessa ação externa.

Galileu ao se deparar com o problema de queda livre dos corpos, proposto segundo a visão aristotélica, passa a questionar se, de fato, a velocidade de um corpo em queda livre depende de quão pesado ele é, pois para Aristóteles a velocidade de queda de corpos mais pesados seria maior que de corpos mais leves. Galileu através de seus estudos propõe que os corpos diferentes, em queda livre, devem chegar ao chão com uma diferença muito pequena que poderia essa ser desconsiderada, isso para ele vem do fato de que em queda os corpos recebem incrementos de velocidades iguais em intervalos de tempo iguais definindo isso como movimento uniformemente acelerado. Mas ao ser questionado acerca do causador dessa aceleração constante, ele desvia do problema justificando que antes de conhecer o causador, seria necessário termos uma descrição do fenômeno. O trabalho produzido por Galileu começava a deixar de lado a mecânica aristotélica de uma forma inovadora, diferente do que vinha sendo feito há muito tempo, ao adicionar a prática experimental através de processos de medidas repetitivas, e análise das mesmas. Galileu criava uma nova forma de fazer ciência, além disso, outro fator importante dos resultados do seu trabalho foi a admissão de existência de vácuo que os corpos em queda livre têm aceleração constante, quando desconsiderado a ação da resistência do ar e a diferença das massas.

Para Newton, a variação do momento linear resulta de um processo de ação e reação do corpo com o meio onde o ocorre o movimento, por exemplo, ao empurrar um bloco podemos perceber que o bloco empurra nossos dedos com ação contraria até que vencida a inércia do mesmo entre em movimento, essa relação de ação e reação é a terceira lei de Newton para o movimento que descreve um processo de interação que tem importância ímpar para esse trabalho. A análise de interações na Física de questões ligadas ao preenchimento de todo o espaço por uma matéria sutil permeando todos os corpos (Aristóteles), a existência de eflúvios elétricos e magnéticos, dentre outros fluidos, as linhas de força de Faraday, e a proposta maxwelliana de ação local, bem como questões ligadas ao vácuo, a proposta newtoniana de ação à distância, seguida por Coulomb, Ampère e Weber, demonstram que temos que nos debruçar sobre a história do movimento se quisermos desvendar as questões que se relacionam com a ação à distância e a ação local no estudo da radiação e da matéria.

\section{CONSIDERAÇÕES FINAIS (ou Conclusão)}

Essa abordagem histórica permite perceber também que a construção do conhecimento que temos hoje acerca de processos de interações na Física não foi de forma linear. Durante o seu desenvolvimento percebemos que, de certa forma, recebe influência direta de questões sociais como, por exemplo, a influência da religião na ciência em determinadas épocas, e o destaque recebido pelos filósofos gregos no estudo da ciência, talvez tenha sido porque a Grécia havia se tornado rota de passagem de navios que ligavam o oriente com o ocidente e devido ao fluxo de pessoas possibilitando troca de informações gerando conhecimento.

Um fato importante que deve ser destacado aqui é a importância dos resultados gerados pelo trabalho de Maxwell, em sua transição da ideia de linhas de força proposta por Faraday, para a ideia de um fluido que permeia todo espaço, e que o leva ao conceito de campo. Maxwell, hoje considerado um dos mais importantes nomes dos responsáveis pelo estudo do eletromagnetismo, fez uma síntese das principais leis propostas por: Coulomb, Oersted, Ampère entres outros, gerando basicamente quatro equações que regem os estudos do eletromagnetismo. E essas satisfazem a equação de 
onda, o que possibilitou obter um valor aproximado para velocidades de perturbações eletromagnéticas, e percebeu que esse valor era próximo da velocidade de propagação da luz.

Como continuidade desse trabalho a ideia é continuar o estudo do movimento tendo como principal objetivo estudar mais questões que resultam do processo de descrição de interações levando em conta a ação local e a ação à distância.

\section{REFERÊNCIAS}

PONCZEK L.I.Roberto.; “Origens e Evolução das Ideias da Física” Cáp I.Salvador,BA :UFBA, 2002.

ASSIS, André K. T. Interações na Física - Ação à Distância versus Ação por Contato. In: Estudos de História e Filosofia das Ciências: Subsídios para Aplicação no Ensino, C. C. Silva (Org.), São Paulo: Editora Livraria da Física, p. 87-102, 2006.

SILVA, Marcos Correa da; KRAPAS, Sonia. Controvérsia ação à distância/ação mediada: abordagens didáticas para o ensino das interações físicas. Revista Brasileira de Ensino de Física, v. 29, n. 3, p. 471-479, 2007.

TORT, Alexandre C. CUNHA, Alexander M. ASSIS, A.K.T. Uma tradução de um texto de Maxwell sobre a ação à distância. Revista Brasileira de Ensino de Física, v. 26, n. 3, p. 273-282 (2004).

PSSC - PHYSICAL SCIENCE STUDY COMMITTE. Física parte 3, Cap. XX. Editora Edart, São Paulo, 1965.

ROCHA, José Fernando M.O conceito de "campo" em sala de aula- uma abordagem histórico-conceitual. Revista Brasileira de Ensino de Física, v.31,n.1. 1604(2009).

ASSIS E PESSOA. "Experimento do Balde e Espaço Absoluto: O espaço e o tempo são absolutos ou relativos?". Filosofia da Física Clássica cap. IV. USP, 2006. 